\title{
Assessment of genetic diversity using microsatellite markers to compare donkeys (Equus asinus) with horses (Equus caballus)
}

\author{
Su Min Kim ${ }^{1, a}$, Sung Wook Yun ${ }^{2, a}$, and Gil Jae Cho ${ }^{1,2, *}$
}

\section{* Corresponding Author: Gil Jae Cho Tel: +82-053-950-5978, \\ Fax: +82-053-950-5955, \\ E-mail: chogj@knu.ac.kr}

${ }^{1}$ College of Veterinary Medicine, Kyungpook National University, Daegu 41566, Korea ${ }^{2}$ College of Veterinary Medicine and Institute of Equine Medicine, Kyungpook National

University, Daegu 41566, Korea

${ }^{a}$ Contributed equally to this work.

ORCID

Su Min Kim

https://orcid.org/0000-0002-8502-8912 Sung Wook Yun

https://orcid.org/0000-0002-8132-2778 Gil Jae Cho

https://orcid.org/0000-0001-6848-7335

Submitted Dec 21, 2020; Revised Mar 10, 2021; Accepted Apr 20, 2021
Objective: The study aimed to evaluate the diversity of donkey populations by comparing with the diversity of Thoroughbred and Jeju Halla horses; identified breeding backgrounds can contribute to management and conservation of donkeys in South Korea.

Methods: A total of 100 horse (50 Thoroughbreds and 50 Jeju Halla horses) and 79 donkeys samples were genotyped with 15 microsatellite markers (AHT4, AHT5, ASB2, ASB17, ASB23, CA425, HMS1, HMS2, HMS3, HMS6, HMS7, HTG4, HTG10, LEX3, and VHL20), to identify genetic diversity and relationships among horses and donkeys.

Results: The observed number of alleles per locus ranged from 1 (ASB17, HMS1) to 14 (AHT5), with a mean value of 4.87, 8.00, and 5.87 in Thoroughbreds, Jeju Halla horses, and donkeys, respectively. Of the 15 markers, AHT4, AHT5, ASB23, CA425, HMS2, HMS3, HTG4, HTG10, and LEX3 loci had relatively high polymorphism information content (PIC) values $(\mathrm{PIC}>0.5)$ in these three populations. Mean levels of genetic variation were $\mathrm{H}_{\mathrm{E}}$ $=0.6721$ and $\mathrm{H}_{\mathrm{O}}=0.6600$ in Thoroughbreds, $\mathrm{H}_{\mathrm{E}}=0.7898$ and $\mathrm{H}_{\mathrm{O}}=0.7100$ in Jeju Halla horses, and $\mathrm{H}_{\mathrm{E}}=0.5635$ and $\mathrm{H}_{\mathrm{O}}=0.4861$ in donkeys. Of the 15 loci in donkeys, three loci had negative inbreeding coefficients (FIS), with a moderate mean FIS (0.138). The FIS estimate for the HTG4 marker was highest (0.531) and HMS6 marker was lowest (-0.001). The total probability of exclusion value of 15 microsatellite loci was 0.9996 in donkeys.

Conclusion: Genetic cluster analysis showed that the genetic relationship among 79 donkeys was generally consistent with pedigree records. Among the three breeds, donkeys and Thoroughbred horses formed clearly different groups, but the group of Jeju Halla horses overlapped with that of Thoroughbred horses, suggesting that the loci would be suitable for donkey parentage testing. Therefore, the results of this study are a valid tool for genetic study and conservation of donkeys.

Keywords: Donkey; Horse; Microsatellite Marker; South Korea

\section{INTRODUCTION}

The Equidae family includes a single genus Equus, which contains four subgenera with eight species. The subgenus Equus includes Equus (E.) caballus (domestic horses and Przewalski's or Mongolian wild horses), subgenus Asinus includes E. asinus (donkeys), E. hemionus (Onagers and Asian wild assess), and E. kiang (Kiangs). The subgenus Dolichohippus includes only E. grevyi (Grevy's zebras) and the subgenus Hippotigris includes E. zebra (mountain zebras), E. burchelli (Burchell's or plains zebras), and E. quagga (Quaggas) [1]. The domestication of E. asinus is assumed to have occurred $\sim 6,000 \mathrm{BC}$ in North Africa (particularly near present-day Egypt) from Nubian and Somali wild assess [2]. For centuries, E. asinus has been used by humans primarily for transportation and it remains an important work animal in economically challenged areas [3]. Approximately 5.9 million E. asinus exist globally and most of them are economically essential in third-world countries. Unlike other whole-hoofed animals, E. asinus has not been sufficiently studied; they are domesti- 
cally bred mostly for experience, to tow tourist carriages, or for meat; however, there is little data for bloodlines of domestically bred donkeys. At present, in South Korea, 1,000 donkeys and $\sim 27,000$ domestic horses exist, including 12,000 Thoroughbreds, 1,000 individuals from other horse breeds (e.g., Warmblood, Quarter horse), and 14,000 native horses (the Jeju Halla horse), of which 5,000 Jeju horses which was designated as natural monument No. 347 by the government [4].

DNA analysis using microsatellite markers has recently been used in many animal species for identification of individuals, paternity tests, preservation of endangered animals, and phylogenesis based on origin and breeding history. In addition, countries throughout the world have widely used microsatellite markers since the mid-1990s for the purposes of examining genetic diversity of domesticated animals, tracking their origin and inherited characteristics, and promoting their preservation $[5,6]$.

Microsatellites are numerous repeats of simple base pair sequences in the genome of an organism, and are widely distributed in short repetitive pieces [7]. Microsatellites have a high mutation rate, over $1 / 10^{4}$ to $1 / 10^{6}$ per generation, and have high specificity to a group; polymorphisms can occur at the individual level as well as at the species level, providing a useful tool for genetic mapping as well as information about heritability of many species of plants and animals including humans [8-12]. Microsatellites commonly have been used for the assessment of genetic diversity, construction of genetic maps, quantitative trait loci mapping, and parentage testing $[13,14]$. Microsatellites in a horse were reported for the first time by Ellegren et al [8] and Marklund et al [11].

The study aimed to evaluate the diversity of donkey populations by comparing with the diversity of Thoroughbred horses and Jeju Halla horses; identified breeding backgrounds can contribute to management and conservation of donkeys in South Korea.

\section{MATERIALS AND METHODS}

\section{Sample collection and DNA extraction}

Genomic DNA was extracted using a MagExtractor System MFX-2000 (Toyobo, Osaka, Japan) according to the manufacturer's protocols [12] from whole blood samples of 79 donkeys and 100 horses (50 Thoroughbreds and 50 Jeju Halla horses [a hybrid cross between Thoroughbreds and Jeju horses]).

\section{Microsatellite markers and analysis}

A total of 15 microsatellite loci (AHT4, AHT5, ASB2, ASB17, ASB23, CA425, HMS1, HMS2, HMS3, HMS6, HMS7, HTG4, HTG10, LEX3, and VHL20) were used for analysis of the Equidae. Polymerase chain reaction (PCR) was performed according to the manufacturer's protocols (Stockmarks, Applied Biosystems, Foster, CA, USA). Of the 15 markers, ASB17, ASB23, CA425, HMS1, and LEX3 markers were conducted by a single PCR.

Multiplex PCR was accomplished using a total volume of $15 \mu \mathrm{L}$ of the following mixture: $40 \mathrm{ng}$ genomic DNA, each primer, $1.25 \mathrm{mM}$ dNTPs, $2.5 \mu \mathrm{L} 10 \times$ reaction buffer, and 5 U Taq polymerase (Applied Biosystems, USA). For a single PCR, $2 \mu \mathrm{L}$ template DNA, $2 \mu \mathrm{L}$ of both 10 pmol forward and reverse primers, and $6.5 \mu \mathrm{L}$ sterile distilled water were mixed in PCR Premix buffer (Qiagen, Hidden, Germany), adjusted to $25 \mu \mathrm{L}$ in total.

PCR amplification was as follows: initial denaturation for $10 \mathrm{~min}$ at $95^{\circ} \mathrm{C}$, followed by 30 cycles at $95^{\circ} \mathrm{C}$ for $30 \mathrm{~s}, 60^{\circ} \mathrm{C}$ for $30 \mathrm{~s}$, and $72^{\circ} \mathrm{C}$ for $1 \mathrm{~min}$. An extension step at $72^{\circ} \mathrm{C}$ for 60 min was added after the final cycle [15]. Multiplex PCR reactions were performed in a GeneAmp PCR System 9700 (Applied Biosystems, USA).

PCR products were tested using an automatic gene analyzer (ABI 3130 xl Genetic Analyzer, Foster, CA, USA); subsequent electrophoresis was done on POP 7 polymer (Applied Biosystems, USA) at $15 \mathrm{kV}$. Using peak row data, the size of alleles (in base pairs) for each marker was determined based on the results of 2015/2016 Horse Comparison Test No. 1 of the International Society for Animal Genetics (ISAG), using GeneMapper Software ver. 4.0 (Applied Biosystems, USA).

\section{Statistical analysis}

Allelic frequencies and the number of alleles per locus were estimated by direct counting from the observed genotype; the observed heterozygosity $\left(\mathrm{H}_{\mathrm{O}}\right)$, expected heterozygosity $\left(\mathrm{H}_{\mathrm{E}}\right)$, number of allelic genes and frequency, and polymorphism information content (PIC) value for each breed across the locus were calculated using Cervus ver. 3.0.3 [16].

The inbreeding coefficient of an individual relative to the subpopulation (FIS) was calculated using FSTAT (Ver. 2.9.3; Goudet, 2001). In addition, we analyzed the genetic distance of each individual based on the shared allele distance using the Microsat package.

\section{RESULTS}

\section{Analysis of genetic diversity}

In our study, 15 microsatellites were used to identify genetic diversity and relationships among horses and donkeys. The observed number of alleles per locus ranged from 1 (ASB17, HMS1) to 14 (AHT5), with a mean value of $4.87,8.00$, and 5.87 in Thoroughbreds, Jeju Halla horses, and donkeys, respectively. Of the 15 markers, AHT4, AHT5, ASB23, CA425, HMS2, HMS3, HTG4, HTG10, and LEX3 loci had relatively high PIC values $(\mathrm{PIC}>0.5)$ in these three species. Mean levels 
Table 1. Number of alleles, heterozygosity, and polymorphism information content of 15 microsatellite markers in 179 donkeys and horses

\begin{tabular}{|c|c|c|c|c|c|c|c|c|c|c|c|c|}
\hline \multirow{2}{*}{ Marker } & \multicolumn{3}{|c|}{ No. of alleles } & \multicolumn{3}{|c|}{ OHet } & \multicolumn{3}{|c|}{ EHet } & \multicolumn{3}{|c|}{ PIC } \\
\hline & DK & TB & $\mathrm{JH}$ & DK & TB & JH & DK & TB & $\mathrm{JH}$ & DK & TB & JH \\
\hline AHT4 & 6 & 4 & 6 & 0.6076 & 0.7800 & 0.6400 & 0.7102 & 0.6919 & 0.8081 & 0.6547 & 0.6547 & 0.7686 \\
\hline ASB2 & 2 & 6 & 8 & 0.4557 & 0.7600 & 0.9200 & 0.4605 & 0.8135 & 0.8121 & 0.3529 & 0.7777 & 0.7755 \\
\hline ASB17 & 1 & 5 & 13 & 0.0000 & 0.6400 & 0.7400 & 0.0000 & 0.7206 & 0.8749 & 0.0000 & 0.6675 & 0.6675 \\
\hline ASB23 & 6 & 6 & 8 & 0.8608 & 0.8000 & 0.7600 & 0.7364 & 0.7966 & 0.8208 & 0.6969 & 0.7562 & 0.7562 \\
\hline HMS2 & 8 & 5 & 9 & 0.7215 & 0.3400 & 0.6200 & 0.7447 & 0.3903 & 0.7570 & 0.6989 & 0.3617 & 0.7076 \\
\hline HMS3 & 6 & 5 & 7 & 0.6456 & 0.5800 & 0.5400 & 0.6177 & 0.6519 & 0.7887 & 0.5473 & 0.5960 & 0.7501 \\
\hline HMS6 & 3 & 4 & 7 & 0.5063 & 0.6400 & 0.6400 & 0.5059 & 0.6236 & 0.7644 & 0.4043 & 0.5655 & 0.7167 \\
\hline HMS7 & 4 & 5 & 6 & 0.2025 & 0.8400 & 0.6800 & 0.2320 & 0.7697 & 0.7661 & 0.2203 & 0.7214 & 0.7189 \\
\hline HTG4 & 8 & 4 & 5 & 0.3544 & 0.5800 & 0.6600 & 0.7819 & 0.5562 & 0.6844 & 0.7461 & 0.4610 & 0.6276 \\
\hline
\end{tabular}

OHet, observed heterozygosity; EHet, expected heterozygosity; PIC, polymorphism information content; DK, donkey; TB, thoroughbred; JH, Jeju Halla horse (crossbred).

of genetic variation were as follows: Thoroughbred, $\mathrm{H}_{\mathrm{O}}=$ 0.6600 and $\mathrm{H}_{\mathrm{E}}=0.6721$; Jeju Halla, $\mathrm{H}_{\mathrm{O}}=0.7100$ and $\mathrm{H}_{\mathrm{E}}=$ 0.7898; and donkey, $\mathrm{H}_{\mathrm{O}}=0.4861$ and $\mathrm{H}_{\mathrm{E}}=0.5635$ (Table 1). Of the 15 loci in the donkey population, three loci had negative inbreeding coefficients and the mean FIS was moderate (0.138). The FIS estimate for HTG4 marker was highest (0.531) and HMS6 marker was lowest $(-0.001)$. The total probability of exclusion value of 15 microsatellite loci was 0.9996 in the donkey population (Table 2).

\section{Population relationship}

Using simple allele-sharing levels to calculate the genetic differences between donkey and horse breeds, a collective genetic analysis was based on individual allele frequency using the analysis with Microsat (Figure 1). Genetic cluster analysis showed that the genetic relationship among 79 donkeys was generally consistent with pedigree records. Among the three breeds, donkeys and Thoroughbreds formed clearly different groups; the Jeju Halla horse formed a group that overlapped with Thoroughbred horses.

\section{DISCUSSION}

Many microsatellite markers have previously been isolated from the horse genome; these microsatellites showed multiple alleles as well as high heterozygosity among European horse breeds such as the Thoroughbred horse [17]. Microsatellites are informative due to their high rates of polymorphism and are useful in paternity testing of animals [13,18-22]; they have been used extensively to examine the structure of closely related populations and breed allocation of animals
[13,20,22-24]. In cattle, pigs, horses, and dogs, pedigree control has been performed on a routine basis in most countries. These controls rely on microsatellite typing that has been standardized through regular comparison tests under the auspices of ISAG.

In South Korea, to meet the demands of the domestic donkey market and secure a better quality of donkeys and donkey meats, it is necessary to select donkeys with excellent pedigrees to begin and enhance donkey breeding. However, currently, in South Korea, investigations of the

Table 2. Statistical analysis of gene diversity per locus, inbreeding coefficient, and exclusion probability in 79 donkeys

\begin{tabular}{lcccc}
\hline Locus & Gene diversity & FIS & PE (1) & PE (2) \\
\hline AHT4 & 0.711 & 0.145 & 0.288 & 0.458 \\
AHT5 & 0.878 & 0.106 & 0.666 & 0.800 \\
ASB2 & 0.461 & 0.011 & 0.105 & 0.176 \\
ASB17 & 0.000 & 0.000 & 0.000 & 0.000 \\
ASB23 & 0.740 & -0.163 & 0.336 & 0.514 \\
CA425 & 0.736 & -0.049 & 0.317 & 0.489 \\
HMS1 & 0.000 & 0.000 & 0.000 & 0.000 \\
HMS2 & 0.745 & 0.031 & 0.337 & 0.513 \\
HMS3 & 0.617 & -0.045 & 0.205 & 0.352 \\
HMS6 & 0.506 & -0.001 & 0.126 & 0.218 \\
HMS7 & 0.232 & 0.128 & 0.027 & 0.122 \\
HTG4 & 0.782 & 0.531 & 0.400 & 0.578 \\
HTG10 & 0.723 & 0.124 & 0.325 & 0.527 \\
LEX3 & 0.779 & 0.529 & 0.400 & 0.581 \\
VHL20 & 0.505 & 0.349 & 0.125 & 0.201 \\
Total & $0.561 *$ & 0.138 & 0.991 & 0.999 \\
\hline
\end{tabular}

FIS, inbreeding coefficient; PE (1), total exclusionary power (first parent); PE (2), total exclusionary power (second parent). 


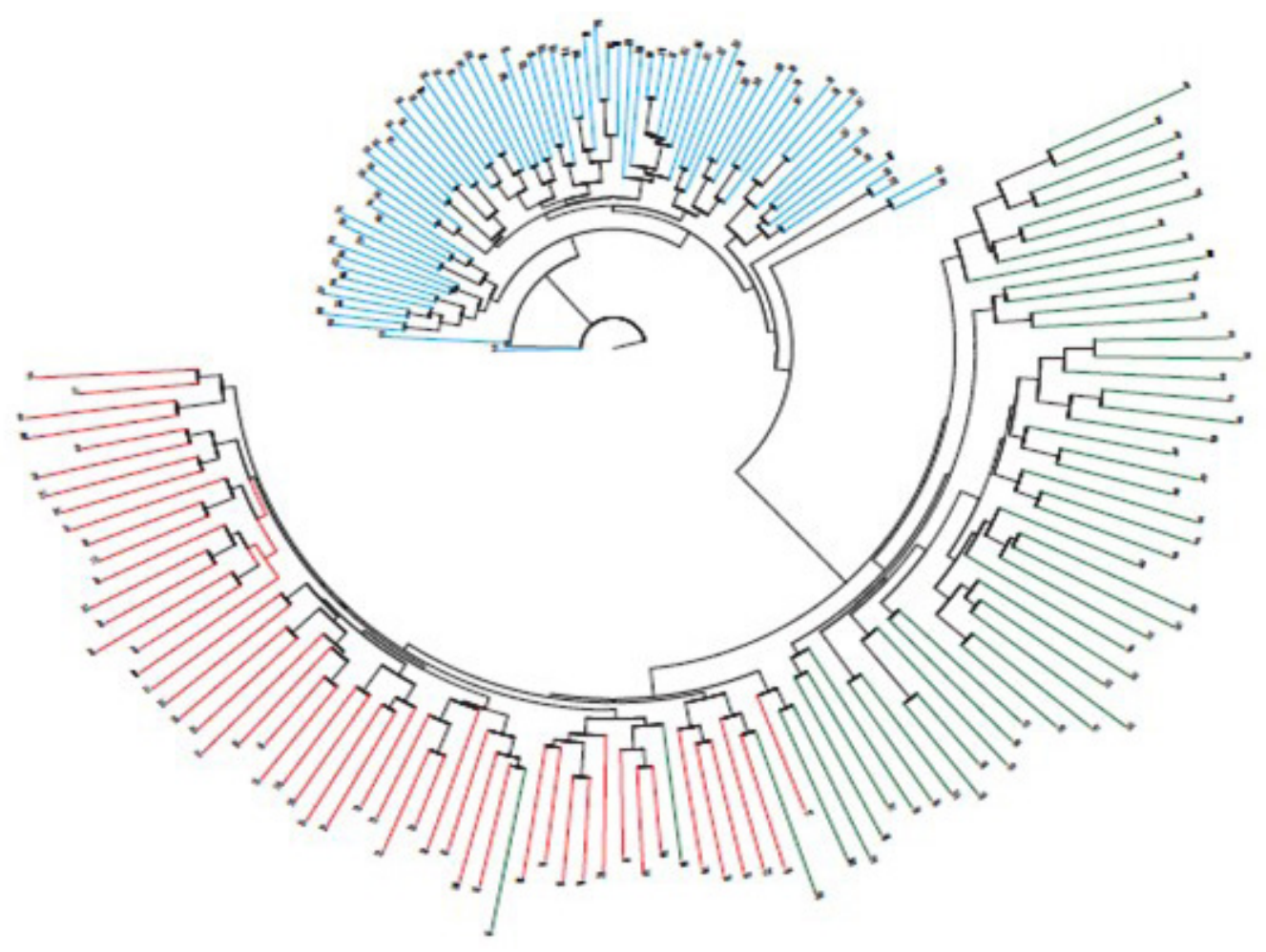

Figure 1. A neighbor-joining dendrogram, constructed from allele-sharing distances among 179 individuals in donkeys and two horse breeds. Blue color, donkey; Green color, Thoroughbred; Red color, Jeju Halla horse.

breeding and genetics of donkeys, compared with other breeds such as the Thoroughbred, the Jeju horse, or the Jeju Halla horse, are insufficient.

Because several loci in the current study had relatively high PIC values (PIC>0.5) in populations examined, it is likely that these markers can be utilized in the differentiation of donkey individuals and for paternity tests. Based on the PIC value of each marker, the validity and reliability of the marker can be estimated; if the PIC value is $>0.5000$, the reliability of the marker is valid for pedigree analysis. If the PIC value is $>0.7000$, it has universal validity for analysis and has a high reliability. An international panel of 13 markers (AHT4, ASB23, HMS2, HMS3, HMS6, HMS7, HMS18, HTG7, HTG10, TKY297, TKY312, TKY337, and TKY343) for donkeys has recently been recommended by ISAG. However, donkeys are raised primarily in the country in which they exist, unlike Thoroughbred horses that are extensively imported and exported; therefore, the nine microsatellite markers identified in this study are considered appropriate for individual identification and parentage verification.

In a single gene locus, an indicator of diversity is heterozygosity. In an association analysis or linkage disequilibrium analysis, higher heterozygosity is more desirable $[9,25,26]$. When multiple groups are mixed, heterozygosity increases, but if there is no interbreeding of groups, heterozygosity is generally related to mutations in the population [27]. For analysis of genetic characteristics using a microsatellite marker, heterozygosity can be judged from the degree of mixing between target populations and other populations. If a pure pedigree is preserved through powerful selection without a mix of species, the value of heterozygosity is low; if there is a mix of different breeds, heterozygosity is high. However, when more individuals are used in a study, heterozygosity is higher, so it may be difficult to judge the mix of species based only on heterozygosity. A collective genetic analysis based on individual allele frequencies indicates that donkeys and Thoroughbred horses formed clearly different groups, but Jeju Halla horses formed a group that overlapped with that of Thoroughbred horses. Jeju Halla horses are a hybrid of Thoroughbred horses and Jeju horses; the inclusion of five Thoroughbred horses within the pedigree likely caused an appearance of their genetic factors in the present analysis.

The donkey had the lowest heterozygosity compared with horse breeds; the FIS of 0.138 indicates that genetic diversity is decreasing due to inbreeding. Low heterozygosity is likely due to few breeding herds of domesticated donkeys and inbreeding produced by a limited number of male horses. Therefore, a breeding program is needed to minimize inbreeding within farms and more stallions should be used for genetic diversity of domestically bred donkeys.

Donkeys in South Korea are less abundant compared with 
horse breeds, but they are very valuable in riding tourism and meat. Therefore, to secure and to preserve genetic diversity of donkeys, systematic management through the selection of stallions and registration of pedigrees are necessary. The evaluation of genetic diversity of donkeys suggests that nine microsatellite markers (AHT4, AHT5, ASB23, CA425, HMS2, HMS3, HTG4, HTG10, and LEX3) could be used for individual identification and parentage verification in donkeys. Although it is currently under discussion whether to use single nucleotide polymorphisms instead of microsatellite DNA markers for parentage verification and individual identification of horses, the results of this study suggest that microsatellites are also valid as a tool for the genetic study and conservation of donkeys.

\section{CONFLICT OF INTEREST}

We certify that there is no conflict of interest with any financial organization regarding the material discussed in the manuscript.

\section{ACKNOWLEDGMENTS}

This research was supported by the National Research Foundation of Korea, funded by the Ministry of Education, Science and Technology (NRF-2020R1I1 A3067905).

\section{REFERENCES}

1. Nowak RM, Paradiso JL. Walker's mammals of the world. 4th ed. Baltimore, MD, USA: The Johns Hopkins University Press; 1983.

2. Beja-Pereira A, England PR, Ferrand N, et al. African origins of the domestic donkey. Science 2004;304:1781. http://doi. org/10.1126/science. 1096008

3. Polidori P, Vincenzetti S. Protein profile characterization of donkey milk. In: Hurley WL, editor. Milk protein. Rijeka, Croatia: InTech Publisher; 2012. pp. 215-32. http://doi.org/ $10.5772 / 48982$

4. Shin SK, Kim SM, Lioyd S, Cho GJ. Prevalence of hoof disorders in horses in South Korea. The Open Agric J 2020; 14:25-9.

5. Arranz JJ, Bayon Y, Primitivo FS. Comparison of protein markers and microsatellites in differentiation of cattle populations. Anim Genet 1996;27:415-9. https://doi.org/10.1111/ j.1365-2052.1996.tb00508.x

6. Bjornstad G, Nilsen NO, Roed KH. Genetic relationship between Mongolian and Norwegian horses. Anim Genet 2003;34:55-8. https://doi.org/10.1046/j.1365-2052.2003.009 22.x

7. Li K, Fan B, Zhao S, Peng Z, Chen Y, Moran C. Analysis of diversity and genetic relationships between four Chinese
Indigenous pig breeds and one Australian commercial pig breed. Anim Genet 2000;31:322-5. https://doi.org/10.1046/ j.1365-2052.2000.00649.x

8. Ellegren H, Jihansson M, Sandberg K, Andersson L. Cloning of highly polymorphic microsatellites in the horse. Anim Genet 1992;23:133-42. https://doi.org/10.1111/j.1365-2052. 1992.tb00032.x

9. Kang BT, Kim KS, Min MS, et al. Microsatellite loci analysis for the genetic variability and the parentage test of five dog breeds in South Korea. Genes Genet System 2009;84:24551. https://doi.org/10.1266/ggs.84.245

10. Lipinski MJ, Amigues $Y$, Blasi M, et al. An international parentage and identification panel for the domestic cat (Felis catus). Anim Genet 2007;38:371-7. https://doi.org/10.1111/ j.1365-2052.2007.01632.x

11. Marklund S, Ellegren H, Eriksson S, et al. Parentage testing and linkage analysis in the horse using a set of highly polymorphic microsatellites. Anim Genet 1994;25:19-23. https:// doi.org/10.1111/j.1365-2052.1994.tb00050.x

12. Tozaki T, Kakoi H, Mashima S, et al. Population study and validation of paternity testing for Thoroughbred horses by 15 microsatellite loci. J Vet Med Sci 2001;63:1191-7. https:// doi.org/10.1292/jvms.63.1191

13. Li C, Wang Z, Liu B, et al. Evaluation of the genetic relationship among ten Chinese indigenous pig breeds with twentysix microsatellite markers. Asian-Australas J Anim Sci 2004; 17:441-4. https://doi.org/10.5713/ajas.2004.441

14. Zhang JH, Xiong YZ, Deng CY. Correlations of genic heterozygosity and variances with heterosis in a pig population revealed by microsatellite DNA marker. Asian-Australas J Anim Sci 2005;18:620-5. https://doi.org/10.5713/ajas.2005. 620

15. Dimsoski P. Development of a 17-plex microsatellite polymerase chain reaction kit for genotyping horses. Croat Med J 2003;44:332-5.

16. Kalinowski ST, Taper ML, Marshall TC. Revising how the computer program CERVUS accommodates genotyping error increases success in paternity assignment. Mol Ecol 2007;16:1099-106. https://doi.org/10.1111/j.1365-294X.2007. 03089.x

17. Tozaki T, Takezaki N, Hasegawa T, et al. Microsatellite variation in Japanese and Asian horses and their phylogenetic relationship using a European horse outgroup. J Hered 2003; 94:374-80. https://doi.org/10.1093/jhered/esg079

18. Bowling AT, Eggleston-Scott ML, Byrns G, Clark RS, Dileanis D, Wictum E. Validation of microsatellite markers for routine horse parentage testing. Anim Genet 1997;28:247-52. https:// doi.org/10.1111/j.1365-2052.1997.00123.x

19. Cho GJ, Yang YJ, Kang HS, Cho BW. Genetic diversity and validation of microsatellite markers for Jeju native horse parentage testing. Korean J Genet 2002;24:359-65.

20. Kim KS, Choi CB. Genetic structure of Korean native pig 
using microsatellite markers. Korean J Genet 2002;24:1-7.

21. Cho GJ, Cho BW. Microsatellite DNA typing using 16 markers for parentage verification of the Korean native horse. AsianAustralas J Anim Sci 2004;17:750-4. https://doi.org/10.5713/ ajas.2004.750

22. Sun W, Chang H, Ren HZ, et al. Genetic differentiation between sheep and goats based on microsatellite DNA. Asian-Australas J Anim Sci 2004;17:583-7. https://doi.org/ 10.5713/ajas.2004.583

23. Yoon DH, Kong HS, Oh JD, et al. Establishment of an individual identification system based on microsatellite polymorphisms in Korean cattle (Hanwoo). Asian-Australas J Anim Sci 2005;18:762-6. https://doi.org/10.5713/ajas.2005.762

24. Cho GJ. Microsatellite polymorphism and genetic relationship in dog breeds in Korea. Asian-Australas J Anim Sci 2005;18:
1071-4. https://doi.org/10.5713/ajas.2005.1071

25. Rossel S, Marshall F, Peters J, Pilgram T. 2008. Domestication of the donkey: timing, processes, and indicators. Proc Natl Acad Sci USA 2009;105:3715-20. https:// doi.org/10.1073/ pnas.0709692105

26. Van de Goor LHP, Panneman H, van Haeringen WA. A proposal for standardization in forensic equine DNA typing: allele nomenclature for 17 equine-specific STR loci. Anim Genet 2010;41:122-7. https://doi.org/10.1111/j.1365-2052. 2009.01975.x

27. Oberbauer AM, Belanger JM, Grossman DI, Regan KR, Famula TR. Genome-wide linkage scan for loci associated with epilepsy in Belgian shepherd dogs. BMC Genet 2010; 11:35. https://doi.org/10.1186/1471-2156-11-35 